\title{
The influence of anatomical variations of the cystic artery inside Calot's triangle on the surgical procedure in patients with carbon dioxide pneumoperitoneum
}

\author{
Kamil Torres ${ }^{1,2}$, Anna Torres ${ }^{2}$, Andrzej Chrościcki', Grzegorz Staśkiewicz ${ }^{2,3}$, Jan Kachaniuk ${ }^{1}$, Łukasz Pietrzyk ${ }^{2}$, \\ Sebastian Radej ${ }^{2}$, Marcello Ceccaroni ${ }^{4}$, Andrzej Drop ${ }^{3}$, Ryszard Maciejewski ${ }^{2,5}$ \\ 1Department of General Surgery, District Specialist Hospital, Lublin, Poland \\ 2Laboratory of Biostructure, Human Anatomy Department, Medical University of Lublin, Poland \\ 3Department of Radiology and Nuclear Medicine, Medical University of Lublin, Poland \\ ${ }^{4}$ Gynecologic Oncology Division, European Gynecology Endoscopy School, Sacred Heart Hospital, Negrar (Verona), Italy \\ ${ }^{5}$ Department of Medical Emergency, UITS, Rzeszow, Poland
}

Videosurgery and other miniinvasive techniques 2011; 6 (2): 57-63

DOI: 10.5114/wiitm.2011.23211

\begin{abstract}
Introduction: Laparoscopic cholecystectomy is one of the most frequently performed procedures in surgical wards. Proper anatomical identification of structures within the triangle of Calot is essential for the procedure safety.

Aim: To evaluate demographic, clinical and anatomical characteristics of 84 patients who underwent laparoscopic cholecystectomies.

Material and methods: Anatomical characteristics of Calot's triangle were correlated with body mass index, gender and age of patients as well as with time of the surgery, type of vascular ligation, presence of adhesions, postoperative bleeding, bile leakage and use of a harmonic scalpel. Additionally, patients' demographic data were analysed and compared with data from other patients from Lublin's state.

Results: Obtained anatomical relations of the cystic artery were classified into 2 groups. Group one had typical position of the cystic artery within Calot's triangle. Variants were included in group two. Variants of cystic artery were observed more frequently in females.

Conclusions: We found that the classification of Skandalakis et al. was very detailed, but too complex to be implemented in everyday practice. Therefore we propose a simplified classification which could be used as a practical tool to determine the type of anatomical variation and preserve the safety of the procedure.
\end{abstract}

Key words: laparoscopy, carbon dioxide pneumoperitoneum, cholecystectomy, cystic artery, Calot's triangle.

\section{Introduction}

Cholecystolithiasis is one of the most common causes of surgical hospitalization in the Lublin region. Laparoscopic cholecystectomy has become the gold standard for the treatment of cholelithiasis. Compared to the classic open abdomen technique, the laparoscopic one is less invasive, requires a shorter hospitalization period and provides a better cosmetic effect. Despite its obvious advantages, the laparoscopic technique, which usually utilizes carbon dioxide $\left(\mathrm{CO}_{2}\right)$ pneumoperitoneum, can cause various complications including shoulder tip pain or more frequent postoperative nausea and vomiting as well as 
iatrogenic biliary injury and intra- or postoperative arterial haemorrhage [1-4]. Such surgical complications are likely to occur due to improper recognition of the structures within Calot's triangle [2].

Calot's triangle is defined as the area bordered by the cystic duct, common hepatic duct and lower edge of the liver [5]. This region and the hepatobiliary triangle are considered to be among the most variable anatomical structures $[2,6]$.

As laparoscopic cholecystectomy is one of the most commonly performed surgical procedure, detailed knowledge of Calot's triangle anatomy as well as its variations is essential in everyday practice. The great variety of anatomical origins of the cystic artery might create problems with proper recognition and dissection of structures during laparoscopic cholecystectomy. Technical difficulties resulting from inadequate identification of the structures inside the triangle might be especially problematic in terms of recognition and might lead to injuries of the cystic artery or bile ducts, which are the most common complications of laparoscopic cholecystectomy $[2,7]$.

That is why several classifications and techniques were introduced in order to standardize the procedure and decrease the number of iatrogenic injuries $[2,8,9]$.

\section{Aim}

The aim of the present study was to evaluate the correlation between anatomical conditions inside Calot's triangle, operative parameters (time of the procedure, use of a harmonic knife), postoperative complications (haemorrhage and bile leakage) and

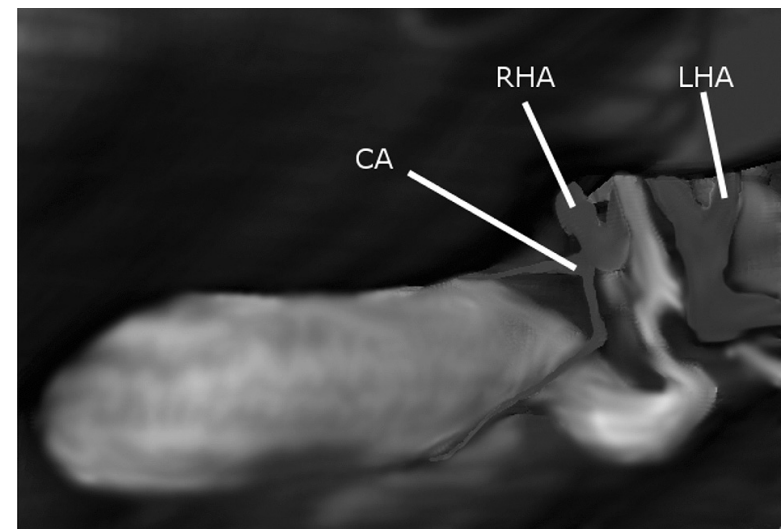

Figure 1. Typical origin of cystic artery (CA) from right hepatic artery (RHA). Left hepatic artery (LHA). Antero-medial view patients' demographic data. Additionally we evaluated the utility of the anatomical classification introduced by Skandalakis et al. in laparoscopic cholecystectomies.

\section{Material and methods}

The study included 84 patients who underwent laparoscopic cholecystectomy. Patients were operated on by two surgeons (ACh and KT) between January and December 2009 at the Department of General Surgery of the District Specialist Hospital of Lublin, Poland. All the patients underwent preoperative diagnostics which included physical and ultrasound examination as well as laboratory workup and were qualified for elective surgery.

All laparoscopic cholecystectomies were performed under general anaesthesia using the standard "four ports technique". Pneumoperitoneum was created after introducing a Veress needle below the umbilicus. After obtaining proper values of intraabdominal pressure $(12-14 \mathrm{mmHg})$ the video port (umbilical) and 3 other operating ports were introduced (two $5 \mathrm{~mm}$, and one $10 \mathrm{~mm}$ ). The gallbladder was removed after detailed identification of the structures within Calot's triangle. The topography of the cystic artery and bile ducts was categorized using Skandalakis' classification. The origin of the cystic artery has been divided into 5 types: $\mathrm{A}$ - from the right hepatic artery (Figure 1); B - from the common hepatic artery, its bifurcation, or from the left hepatic artery; C - from the gastro-duodenal artery; D and E the cystic artery reaches the gall bladder at the fundus or distal part of the body as a recurrent artery (from the superficial side type D, or deep type E) [10-12].

The characteristics of the operated population are presented in Table I.

Types of cystic artery origin according to Skandalakis et al., as well as domination of the superficial or deep branch of the cystic artery were correlated with patients' demographic data (age, gender, body mass index-BMI), intraoperative parameters (occurrence of adhesions, use of harmonic knife, type of haemostasis of the cystic artery) and occurrence of postoperative complications (haemorrhage and bile leakage). The presence of any type of adhesions was included in the study protocol. Obtained results were statistically analysed.

The demographic data of the patients included in our study were compared with data of patients hos- 
pitalized due to cholelithiasis in the state of Lublin. Data were obtained from the Public Health Centre in Lublin. Results were presented as the median and the percentage.

For statistical analysis, the Mann-Whitney U, Kruskal-Wallis and $\chi^{2}$ tests were used to evaluate the differences between male and female patients. Differences with $p$ value less than 0.05 were regarded as statistically significant. Data were analysed using SPSS Statistics v. 17.0.

\section{Results}

Laparoscopic evaluation revealed that in both groups (male and female) type A was the most common. Groups B \& E were the most common types in male patients and occurred with the same frequency. Type $D$ and $E$ were more common in male patients compared to women. Detailed results are presented in Table II.

Interestingly, type C was observed exclusively in females. As type A was the most common in both genders we grouped types $B, C, D$ and $E$ into one class (type $\mathrm{O}$ ). The frequency of the cystic artery variants differed between the groups. Type A was more common in males whereas type $O$ variation of the point of origin was more common in the female group $(45.6 \%)$ than the male group $(12.5 \%)$. Results are presented in Table III.

Type A occurred in $87.5 \%$ of female patients and was more common in male than female patients.

Type $\mathrm{O}$ variants occurred significantly more often in the female group $(p<0.05)$. In both groups laparoscopic evaluation of the cystic artery within Calot's triangle revealed more frequent domination of the deep branch. Domination of the branches of the cystic artery is presented in Table IV.

No correlations between the presence of adhesions or use of a harmonic knife and the duration of surgery were observed. The presence of adhesions and use of a harmonic scalpel are presented in Table $\mathrm{V}$.

A positive correlation between BMI $(p=0.013)$ and duration of the surgery was observed. The cystic
Table I. Characteristics of operated population

\begin{tabular}{|lcc|}
\hline Parameter & Male $(n=16)$ & Female $(n=68)$ \\
\hline Age [years] & 60.5 & 54.0 \\
\hline BMI [body mass index] & 27.8 & 28.0 \\
\hline $\begin{array}{l}\text { Duration of the procedure } \\
{[\text { min] - median values }}\end{array}$ & 47.5 & 40.0 \\
\hline Postoperative bile leakage & 0 & 0 \\
\hline Postoperative complications & 0 & 0 \\
\hline Postoperative hospitalization & 3.2 & 3.2 \\
\hline
\end{tabular}

Table II. Percentage of cystic artery types within Calot's triangle in men and women according to Skandalakis et al. classification

\begin{tabular}{|lccccc|}
\hline \multirow{2}{*}{ Gender } & \multicolumn{5}{c|}{ Type of artery } \\
\cline { 2 - 6 } & $\mathrm{A}[\%]$ & $\mathrm{B}[\%]$ & $\mathrm{C}[\%]$ & $\mathrm{D}$ & $\mathrm{E}[\%]$ \\
\hline M & 16.7 & 1.2 & 0.0 & 0.0 & 1.2 \\
\hline $\mathrm{F}$ & 44.0 & 6.0 & 6.0 & 10.7 & 14.3 \\
\hline
\end{tabular}

$M$ - male, $F$-female

Table III. Percentage of typical anatomy of cystic artery - type $\mathrm{A}$, and variations - type $\mathrm{O}$

\begin{tabular}{|lcc|}
\hline \multirow{2}{*}{ Gender } & \multicolumn{2}{c|}{ Type of artery } \\
\cline { 2 - 3 } & $\mathrm{A}[\%]$ & $\mathrm{O}[\%]$ \\
\hline M & 87.5 & 12.5 \\
\hline F & 54.4 & 45.6 \\
\hline
\end{tabular}

Table IV. Domination of branches of cystic artery

\begin{tabular}{|lccc|}
\hline \multirow{2}{*}{ Gender } & \multicolumn{3}{c|}{ Dominating branch } \\
\cline { 2 - 4 } & Deep [\%] & Superficial [\%] & No dominance [\%] \\
\hline M & 60.0 & 20.0 & 20.0 \\
\hline F & 71.4 & 12.5 & 16.1 \\
\hline
\end{tabular}

Table V. Percentage of adhesions and use of harmonic scalpel

\begin{tabular}{|lcccc|}
\hline \multirow{2}{*}{ Gender } & \multicolumn{3}{c|}{ Adhesions } & \multicolumn{2}{c|}{ Use of harmonic scalpel } \\
\cline { 2 - 5 } & Yes [\%] & No [\%] & Yes [\%] & No [\%] \\
\hline M & 10.7 & 8.3 & 2.4 & 16.7 \\
\hline F & 32.1 & 48.8 & 22.6 & 58.3 \\
\hline
\end{tabular}


Table VI. Types of arterial ligation in groups

\begin{tabular}{|lccc|}
\hline \multirow{2}{*}{ Gender } & \multicolumn{3}{c|}{ Types of haemostasis } \\
\cline { 2 - 4 } & Coagulation [\%] & Ligatures [\%] & Clips [\%] \\
\hline M & 4.9 & 0.0 & 14.8 \\
\hline F & 32.1 & 1.2 & 46.9 \\
\hline
\end{tabular}

artery and its branches were ligated by surgical sutures, coagulated or clipped (Table VI). Types of used haemostatic technique did not influence the duration of the procedure $(p=0.455)$.

Medical and demographic data concerning patients hospitalized due to cholelithiasis in the years 2005-2008 were obtained from the Public Health Centre in Lublin and are presented in Tables VII-X.

\section{Discussion}

Laparoscopic cholecystectomy is one of the most common intervention performed in surgical wards.
Proper recognition of the structures within Calot's triangle is essential for the safety of this procedure.

The region of Calot's triangle is one of the most variable anatomical regions of the human body. Many descriptions concerning the points of origin of the cystic artery and its course in this region can be found in the literature [6, 13-20]. The most important steps during laparoscopic cholecystectomy include correct identification of the structures within Calot's triangle and proper dissection and ligation of the cystic artery and bile ducts, which prevent postoperative haemorrhage and bile leakage. Use of the "infundibular" technique might contribute to misidentification of the common bile duct or an aberrant right hepatic duct with the cystic duct [21].

Difficult anatomical conditions which often hamper laparoscopic cholecystectomy facilitated introduction of techniques which aimed to increase the safety of that procedure. Introduction of new techniques that minimize the surgical injury, such as NOTES (natural orifice translumenal endoscopic surgery) or SILS

Table VII. Number of cholelithiasis-related hospitalizations with acute cholecystitis in the Lublin region

\begin{tabular}{|lcccccccc|}
\hline $\begin{array}{l}\text { Age range } \\
\text { [years] }\end{array}$ & \multicolumn{2}{c}{2005} & \multicolumn{2}{c}{2006} & \multicolumn{2}{c}{2007} & \multicolumn{2}{c|}{2008} \\
\cline { 2 - 9 } & $\mathrm{M}(n)$ & $\mathrm{F}(n)$ & $\mathrm{M}(n)$ & $\mathrm{F}(n)$ & $\mathrm{M}(n)$ & $\mathrm{F}(n)$ & $\mathrm{M}(n)$ & $\mathrm{F}(n)$ \\
\hline $18-23$ & 8 & 82 & 13 & 116 & 8 & 109 & 6 & 102 \\
\hline $24-29$ & 32 & 207 & 24 & 192 & 36 & 194 & 31 & 212 \\
\hline $30-40$ & 102 & 426 & 91 & 405 & 85 & 446 & 107 & 422 \\
\hline $41-50$ & 222 & 741 & 197 & 693 & 187 & 657 & 191 & 610 \\
\hline $51-60$ & 335 & 1065 & 332 & 1043 & 363 & 1097 & 316 & 1089 \\
\hline $61-70$ & 354 & 930 & 334 & 846 & 316 & 876 & 347 & 883 \\
\hline 71 and more & 444 & 1253 & 453 & 1183 & 441 & 1176 & 499 & 1134 \\
\hline Total & 1497 & 4704 & 1444 & 4478 & 1436 & 4555 & 1497 & 4452 \\
\hline
\end{tabular}

Table VIII. Number of hospitalizations in Lublin state (urban and rural areas)

\begin{tabular}{|ccccccc|}
\hline Year & Rural region & $\begin{array}{c}\text { Small city less } \\
\text { than 25 000 } \\
\text { inhabitants }\end{array}$ & $\begin{array}{c}\text { City } \\
25 \text { 000-100 000 } \\
\text { inhabitants }\end{array}$ & $\begin{array}{c}\text { City with more } \\
\text { than 100 000 } \\
\text { inhabitants }\end{array}$ & $\begin{array}{c}\text { Other states } \\
\text { or countries }\end{array}$ & Total \\
\hline 2005 & 3203 & 835 & 933 & 1110 & 164 & 6245 \\
\hline 2006 & 2981 & 755 & 1078 & 979 & 167 & 5960 \\
\hline 2007 & 2945 & 795 & 1078 & 1037 & 160 & 6015 \\
\hline 2008 & 2953 & 760 & 1062 & 1010 & 205 & 5990 \\
\hline
\end{tabular}


(single-incision laparoscopic surgery), and at the same time introduce new surgical tools with new, broader possibilities, demand of the surgeon perfect knowledge of the anatomical region [22-25].

Avgerinos et al. presented the "critical view of safety" (CVS) technique, which recommended clearing the triangle of Calot from fat and fibrous tissue, followed by gallbladder removal starting from the lowest portion attached to the gallbladder bed. That cited technique consists in detailed identification of Calot's triangle's structures and the authors stressed its preventive role against bile duct and blood vessel injuries [26].

Tang et al. presented the Observational Clinical Human Reliability Assessment (OCHRA) for laparoscopic cholecystectomy, which was an objective system documenting errors as well as their consequences occurring at all stages of surgery. The assessment can be useful in recognition of difficult anatomical conditions [27].

The technique of subtotal removal of the gallbladder can be used when proper anatomical identification is impossible. In the study performed by Sharp et al. a postoperative follow-up of 314 days was performed. The authors concluded that partial cholecystectomy was a feasible approach in patients with severe inflammation in terms of clinical results [9]. Similarly, Cakmak et al. stated that partial cholecystectomy could be efficiently and safely performed in case of difficulties with the dissection of Calot's triangle [7]. Di Carlo et al. suggested that subtotal cholecystectomy should be considered when deviation of normal anatomy of this region occurred [28]. Despite the development of new techniques such as SILS cholecystectomy the importance of Calot's triangle anatomy cannot be neglected [29]. Injuries of the biliary ducts which occur often in cases of cholelithi-
Table IX. Average time of hospitalization

\begin{tabular}{|lc|}
\hline Year & Average hospital stay [days] \\
\hline 2005 & 6.6 \\
\hline 2006 & 6.08 \\
\hline 2007 & 5.87 \\
\hline 2008 & 5.59 \\
\hline
\end{tabular}

asis with severe cholecystitis and/or peritonitis result from inflammation-induced changes in the topography of Calot's triangle structures which are either hidden within masses of inflammatory tissues (cystic duct) or are adhered to the gallbladder, mimicking its wall (common hepatic bile duct) [30, 31].

For cases connected with problems in recognition of anatomical structures Lee et al. presented a surgical technique in which the Veress needle was introduced via the subcostal arch in order to decompress the gallbladder. Such a manoeuvre facilitated identification of the structures inside Calot's triangle [32]. The technique presented by Sari et al. utilized an intraoperative injection of the fundus of the gall bladder with methylene blue. According to the authors such a procedure was very helpful in avoiding anatomical misidentification [33]. The technique presented by Kunsani et al. was based on identification of the Calot's triangle lymph node, which was used subsequently as a reference point (end point) in the dissection. According to the authors the inflamed and usually enlarged node should be kept lateral during dissection [34].

Apart from inflammation other pathologies including Mirizzi's syndrome may also alter the topography of Calot's triangle. Therefore in cases of Mirizzi's syndrome a preoperative workup including ultrasound and endoscopic retrograde cholangiopan-

Table X. Occurrence of accompanying diseases in patients with cholelithiasis hospitalized in Lublin state

\begin{tabular}{|lcc|}
\hline ICD-10 code & Disease & $\begin{array}{c}\text { Number of patients hospitalized } \\
\text { in 2005-2008 }\end{array}$ \\
\hline I 10 & Essential (primary) hypertension & 398 \\
\hline K 81 & Cholecystitis & 202 \\
\hline K 85 & Acute pancreatitis & 143 \\
\hline I 11 & Hypertensive heart disease & 133 \\
\hline E 11 & Non-insulin-dependent diabetes mellitus & 119 \\
\hline I 48 & Atrial fibrillation and flutter & 114 \\
\hline
\end{tabular}


creatography (ERCP) should be performed to evaluate the anatomy of Calot's triangle's structures. Some authors suggested that in patients with suspected Mirizzi's syndrome an open approach should be considered to avoid misidentification of anatomical structures [35].

Sugita et al. evaluated the topography of cystic arteries and the cystic duct with 64-detector row computed tomography (CT) before laparoscopic cholecystectomy. Their findings were in agreement with surgical records. Analysis of 234 patients revealed that CT was a reliable tool in preoperative assessment of topography within Calot's triangle [36]. However, due to limited access to CT examination and its high cost, this method of preoperative evaluation is of limited application.

Various classifications of the anatomical relations of the cystic artery have been described. Surgical classification by Balija et al. categorized variations of the cystic artery into two groups. Group I referred to its most typical topography occurring in up to $96 \%$ of cases with the point of origin located within the hepatobiliary triangle [13]. Our study revealed type I to be the most frequent as well. Further on Balija et al. distinguished three subgroups among the group I variations. The first subgroup included normal position of the cystic artery, the second subgroup included all cases of cystic artery duplication in Calot's triangle, and the third one included cystic artery deriving from an aberrant hepatic artery. The second group included cystic artery variants originating either from the gastroduodenal artery or from the left hepatic artery. Cystic artery variants belonging to that group could not be found in the hepatobiliary triangle [13].

The present study evaluated the dominance of the branches of the type A cystic artery. Statistical analysis revealed more frequent dominance of the deep branch (60\% in the $M, 71 \%$ in the $F$ group), which is in concordance with the results obtained by other authors $[6,14]$.

In the study performed by Ding et al. three groups of anatomical variants within Calot's triangle were distinguished. Group I represented the most common type of cystic duct course. That type was observed in $85.5 \%$, which is concordant with our results. Group I was subdivided into two subgroups. The first subgroup included cases with the cystic artery originating from the right hepatic artery within Calot's triangle. A double cystic artery was classified as a second subgroup. Group II consisted of cases with the cystic artery originating outside Calot's triangle, including variants branching from the gastroduodenal artery, right hepatic artery variants, liver parenchyma or left hepatic artery. Cases of the gallbladder supplied by two arteries, one originating outside and one inside Calot's triangle, were classified as group III [2].

A variant of a single cystic artery originating from the right hepatic artery which courses around the cystic duct was described by Suzuki et al. However, we have not observed such a variation in our study [37].

The results of our study revealed no influence of the use of an ultrasonic scalpel on duration of the surgery or on quality of ligation of the blood vessels. This is in concordance with the results obtained by Cengiz et al. However, the authors observed less postoperative pain, nausea, blood loss and gallbladder perforation $[8,38]$.

We observed the highest number of patients operated in our department between 51 and 60 years old, which was in accordance with data obtained from the whole Lublin region. Additionally, the majority of the group consisted of female patients. In our study we observed that the majority of patients $(n=64)$ were from rural regions, which was in concordance with the tendency in Lublin's state.

In our study the average hospitalization was 3.2 days and this is shorter than the regional average hospitalization.

Detailed anatomical recognition of Calot's triangle should reduce the incidence of haemorrhage and bile leakage after laparoscopic cholecystectomy. Proper anatomical identification combined with improved surgical techniques can efficiently improve the quality of life of patients after this type of surgery by reducing the incidence of nausea, postoperative pain and other complications [2, 3].

\section{Conclusions}

We found that the classification of Skandalakis et al. was very detailed, but too complex to be implemented in everyday practice. Therefore we propose a simplified classification which could be used as a practical tool to determine the type of anatomical variation and preserve the safety of the procedure.

\section{References}

1. De Silva WM, Sivananthan S, De Silva D, et al. Biliary tract injury during cholecystectomy: a retrospective descriptive review of clinical features, treatment and outcome. Ceylon Med J 2006; 51: 132-6. 
2. Ding YM, Wang B, Wang WX, et al. New classification of the anatomic variations of cystic artery during laparoscopic cholecystectomy. World J Gastroenterol 2007; 42: 5629-34.

3. Hjelmqvist B. Complications of laparoscopic cholecystectomy as recorded in the Swedish laparoscopy registry. Eur J Surg Suppl 2000; 585: 18-21.

4. McKenzie S, Schwartz R. The management of bile duct injuries occurring during laparoscopic cholecystectomy. Curr Surg 2006; 63: 20-3.

5. Rocko JM, Di Gioia JM. Calot's triangle revisited. Surg Gynecol Obstet 1981; 153: 410-4.

6. Hugh TB, Kelly MD, Li B. Laparoscopic anatomy of the cystic artery. Am J Surg 1992; 163: 593-5.

7. Cakmak A, Genç V, Orozakunov E, et al. Partial cholecystectomy is a safe and efficient method. Chirurgia (Bucur) 2009; 104: 701-4.

8. Cengiz Y, Dalenbäck J, Edlund G, et al. Improved outcome after laparoscopic cholecystectomy with ultrasonic dissection: a randomized multicenter trial. Surg Endosc 2010; 24 :624-30.

9. Sharp CF, Garza RZ, Mangram AJ, et al. Partial cholecystectomy in the setting of severe inflammation is an acceptable consideration with few long-term sequelae. Am Surg 2009; 75: 249-52.

10. Skandalakis JE, Gray SW, Ricketts RR, et al. The extrahepatic biliary ducts of the gallbladder. $2^{\text {nd }}$ ed. Baltimore, Williams \& Wilkins 1994.

11. Skandalakis JE, Skandalakis PN, Skandalakis LJ. Surgical anatomy and technique. Springer-Verlag New York Inc, 2000

12. Skandalakis JE, Skandalakis LJ, Skandalakis PN, et al. Hepatic surgical anatomy. Surg Clin North Am 2004; 84: 413-35.

13. Balija M, Huis M, Nikolić V, et al. Laparoscopic visualization of the cystic artery anatomy. World J Surg 1999; 23: 703-7.

14. Chen TH, Shyu JF, Chen CH, et al. Variations of the cystic artery in Chinese adults. Surg Laparosc Endosc Percutan Tech 2000; 10: 154-7.

15. Cushieri A, Dubois F, Mouiel J, et al. The European experience with laparoscopic cholecystectomy. Am J Surg 1991; 161: 385-7.

16. Dąbrowiecki S, Szczęsny W. Miejsce laparoskopii we współczesnym postępowaniu diagnostycznym. Wiedeochirurgia i inne techniki małoinwazyjne 2006; 1: 33-9.

17. Durić B, Ignajatović D, Zivanović V. New aspects in laparoscopic cystic artery anatomy. Acta Chir lugosl 2000; 47: 105-7.

18. Futara G, Ali A, Kinfu Y. Variations of the hepatic and cystic arteries among Ethiopians. Ethiop Med J 2001; 39: 133-42.

19. Hobbs MS, Mai Q, Knuiman MW, et al. Surgeon experience and trends in intraoperative complications in laparoscopic cholecystectomy. Br J Surg 2006; 93: 844-53.

20. Loffeld RJLF. The consequences of lost gallstones during laparoscopic cholecystectomy. Neth J Med 2006; 64: 364-6.

21. Strasberg SM. Error traps and vasculo-biliary injury in laparoscopic and open cholecystectomy. J Hepatobiliary Pancreat Surg 2008; 15: 284-92.

22. Michalik M, Orłowski M, Frask A, Małek A, Maciejewski K. NOTES cholecystectomy - the first experience in Poland. Videosurgery and other miniinvasive techniques 2009; 4: 42-5.

23. Kurpiewski W, Pesta W, Kowalczyk M, et al. SILS cholecystectomy - our first experiences. Videosurgery and other miniinvasive techniques 2009; 4: 91-4.
24. Michalik M, Orłowski M, Frask A, et al. LESS (laparo-endoscopic single-site surgery) right hemicolectomy. Videosurgery and other miniinvasive techniques 2009; 4: 164-7.

25. Modrzejewski A, Śledź M, Chęciński P, et al. Carcinoid tumour of the gallbladder: laparoscopic resection and review of the literature. Videosurgery and other miniinvasive techniques 2009; 4: 72-5.

26. Avgerinos C, Kelgiorgi D, Touloumis Z, et al. One thousand laparoscopic cholecystectomies in a single surgical unit using the "critical view of safety" technique. J Gastrointest Surg 2009; 13: 498-503.

27. Tang B, Hanna GB, Joice P, et al. Identification and categorization of technical errors by Observational Clinical Human Reliability Assessment (OCHRA) during laparoscopic cholecystectomy. Arch Surg 2004; 139: 1215-20.

28. Di Carlo I, Pulvirenti E, Toro A, et al. Modified subtotal cholecystectomy: results of a laparotomy procedure during the laparoscopic era. World J Surg 2009; 33: 520-5.

29. Tacchino R, Greco F, Matera D. Single-incision laparoscopic cholecystectomy: surgery without a visible scar. Surg Endosc 2009; 23: 896-9.

30. Michalik M, Frask A, Trybull A, et al. Methods for treatment of gallbladder diseases. Videosurgery and other miniinvasive techniques 2009; 4: 121-5.

31. Rembiasz K, Bobrzyński A, Budzyński A, et al. Analysis of complications of laparoscopic management of abdominal diseases related to extended indications. Videosurgery and other miniinvasive techniques 2010; 5: 53-9.

32. Lee KT, Shan YS, Wang ST, et al. Verres needle decompression of distended gallbladder to facilitate laparoscopic cholecystectomy in acute cholecystitis: a prospective study. Hepatogastroenterology 2005; 52: 1388-92.

33. Sari YS, Tunali V, Tomaoglu K, et al. Can bile duct injuries be prevented? A new technique in laparoscopic cholecystectomy. BMC Surg 2005; 5: 14

34. Kunasani R, Kohli H. Significance of the cystic node in preventing major bile duct injuries during laparoscopic cholecystectomy: a technical marker. J Laparoendosc Adv Surg Tech A 2003; 13: 321-3.

35. Garavello A, Manfroni S, Bellanova G, et al. Mirizzi's syndrome. Evaluation of 3 cases. Ann Ital Chir 2004; 75: 357-61.

36. Sugita R, Yamazaki T, Fujita N, et al. Cystic artery and cystic duct assessment with 64-detector row CT before laparoscopic cholecystectomy. Radiology 2008; 248: 124-31.

37. Suzuki M, Akaishi S, Rikiyama T, et al. Laparoscopic cholecystectomy, Calot's triangle, and variations in cystic arterial supply. Surg Endosc 2000; 14: 141-4.

38. Cengiz Y, Jänes A, Grehn A, et al. Randomized trial of traditional dissection with electrocautery versus ultrasonic fundus-first dissection in patients undergoing laparoscopic cholecystectomy. Br J Surg 2005; 92: 810-3. 